TECHNICAL NOTE

\title{
Influence of the coefficient of uniformity on the size and frequency of constrictions in sand filters
}

\author{
H. F. TAYLOR*, C. O’SULLIVAN†, T. SHIRE + and W. W. MOINET§
}

\begin{abstract}
Constrictions between voids control the filtration and permeability properties of granular materials. This study uses high-resolution microcomputed tomography images and discrete-element modelling to analyse two important characteristics of constrictions in granular filters: (a) the constriction size distribution (CSD) and (b) the constriction density per unit volume. The results demonstrate the importance of the particle size distribution (PSD) and void ratio of the granular material in determining the constriction density, with more widely graded materials having more densely spaced constrictions. The PSD is shown to be the main determinant of the CSD, in agreement with previous studies. The data are used to examine proposed approaches to estimate constriction spacing or void size.
\end{abstract}

KEYWORDS: discrete-element modelling; fabric/structure of soils; filters; particle-scale behaviour; permeability

\section{INTRODUCTION}

Void constrictions play an important role in sand filters. Specifically, the size and spacing of void constrictions are the critical characteristics that govern the retention of finer base materials, self-filtration in sands subject to seepage loading (Kézdi, 1979) and sand permeability (Indraratna et al., 2012; Taylor et al., 2017). In this contribution the link is assessed between the filter particle shape and particle size distribution (PSD) and both the constriction size distribution (CSD) and the spatial frequency (spacing) of constrictions. The research considers direct measures of the void space topology from data obtained using both micro-computed tomography (microCT) scans and discrete-element method (DEM) simulations.

\section{METHODOLOGY}

Table 1 summarises the 20 microCT samples considered here. To examine shape effects, two materials were used; sub-angular Leighton Buzzard sand and glass beads (material characteristics are detailed in Taylor et al. (2017)). The sample names indicate the material type (GB for glass beads), the approximate coefficient of uniformity for the PSD $\left(C_{\mathrm{u}}=D_{60} / D_{10}\right.$, where $D_{X}$ is the particle diameter for which $X \%$ of the material by mass is finer) and the density of the sample (L, M and D denoting loose, medium and dense, respectively). Seventeen of the samples have approximately linear PSDs (i.e. linear on a semi-logarithmic PSD plot),

Manuscript received 24 November 2017; revised manuscript accepted 13 March 2018. Published online ahead of print 19 April 2018.

Discussion on this paper closes on 1 August 2019, for further details see p. ii.

Published with permission by the ICE under the CC-BY license. (http://creativecommons.org/licenses/by/4.0/)

* Imperial College London, London, UK.

† Imperial College London, London, UK

(Orcid:0000-0002-0935-1910).

+ University of Glasgow, Glasgow, UK

$\S$ Atkins, Bristol, UK. comprising 11 sand samples and six samples of spherical glass beads. Three sand samples with bilinear PSDs were considered, with the finer parts of the curves having $C_{\mathrm{u}}$ values close to 3 and the coarser parts $C_{\mathrm{u}}$ values close to 1.5 (Fig. 1(b)). The names describe the percentage passing at which the curve changes - for example, BL15 has $C_{\mathrm{u}} \approx 3$ up to approximately $15 \%$ passing. The three scans denoted 'rep' in Table 1 were carried out to confirm repeatability.

The experimental approach used here to obtain samples for microCT scanning broadly follows that described by Fonseca (2011) and is detailed in the work by Taylor (2016). Samples $(38 \mathrm{~mm} \times 76 \mathrm{~mm})$ were prepared by dry deposition in a standard triaxial cell, subjected to an isotropic compressive stress of $30 \mathrm{kPa}$ and then impregnated with an epoxy resin. Once the resin had set, $9 \mathrm{~mm}$ dia. subsamples were extracted by coring to obtain high-resolution microCT images using a Nikon XT-H-224 scanner. The voxel size was approximately $10 \times 10 \times 10 \mu^{3}$. A subvolume was extracted from each scan dataset for detailed analysis; the subvolume dimensions for each dataset are indicated in Table 1.

The PSD data obtained from the images using the bounding box approach described in Fonseca et al. (2012) are included in Fig. 1. In previous studies, edge particles, which are intersected by the image boundaries, were not included when calculating the PSD. This process of removing edge particles introduces a bias in the results; large particles are more likely to intersect the boundaries and hence disproportionately more large particles are ignored in the PSD analysis. To address this systematic error a corrective algorithm, as detailed in the work by Taylor (2016), was applied. This algorithm assigns sizes and partial volumes to the incomplete edge particles based on statistics obtained by window sampling within the image.

The microCT images were reconstructed using the software CT Pro 3D (NikonMetrology, 2013). Representative images are given in Fig. 2. Both the ImageJ software (Rasband, 2012) and Avizo Fire 7.0 (FEIVSG, 2012) were used to analyse the images. The constrictions were identified using watershed segmentation of the void space and the constriction sizes were quantified following Taylor et al. (2015). As discussed in the work by Taylor et al. (2015) and 


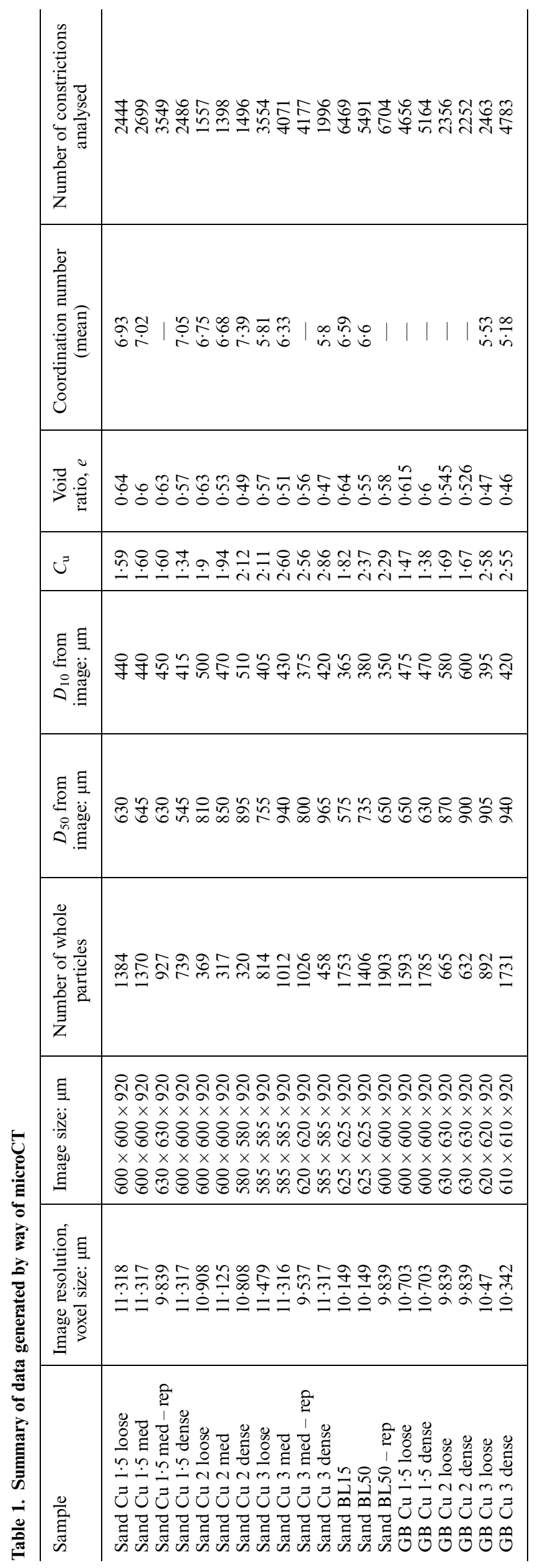

Taylor (2016), the resulting constriction data included information on very small constrictions; as these constrictions were only a few voxels across, the data relating to them are not reliable. In line with the earlier contribution of $\mathrm{Wu}$ et al. (2012), constrictions smaller than $0 \cdot 155 D_{0}$ were excluded from the analysis.

Referring to Table 1, the number of particles considered in each scan is small, numbering less than 2000 whole particles, owing to the practical limitations of obtaining microCT scans with sufficient resolution for detailed analysis. Using DEM, Shire (2014) showed that repeatable CSD data require 800 particles for a $C_{\mathrm{u}}$ of $1 \cdot 5$. These considerations motivated the repeat scans noted in Table 1.

Furthermore, to ensure robust conclusions could be drawn, the data analysis included a re-analysis of existing DEM data. The DEM dataset (summarised in Table 2) was detailed in Shire \& O'Sullivan (2016); the particles were spherical, the large-scale atomic/molecular massively parallel simulator (LAMMPS) code (Plimpton, 1995) was used and the samples were isotropically compressed from an isotropic cloud using periodic boundaries. As in the microCT study, the PSDs considered were either linear or bilinear (on a $\log _{10}$ scale). For these virtual samples, constrictions were identified using the triangulation-based method proposed by Reboul et al. (2010); a user-defined merging threshold (Al-Raoush et al., 2003) of 50\% was adopted. Shire et al. (2016) compared the triangulation method with the microCT approach used for the experimental data and found that the results were broadly similar.

\section{RESULTS \\ Constriction size distribution}

The CSD data for the samples listed in Tables 1 and 2 are presented in Fig. 3 as cumulative distributions by number. To enable direct comparison of the samples, the data in Fig. 3 are normalised by the smallest particle diameter $\left(D_{0}\right)$. Referring to Fig. 3(a), in agreement with the DEM data in Shire \& O'Sullivan (2016) (included here as Fig. 3(c) for reference), the range of constriction sizes increases as the coefficient of uniformity increases. While Shire and O'Sullivan reported a lack of sensitivity of the CSD to increases in the $C_{\mathrm{u}}$ beyond 3 , microCT samples with $C_{\mathrm{u}}>3$ contained such a wide range of particle sizes that the resolution of the smallest particles was insufficient for the required data analysis. Also in agreement with Shire \& O'Sullivan (2016), the influence of density is less marked than the influence of $C_{\mathrm{u}}$. Vincens et al. (2013), who also highlighted the dominant influence of $C_{\mathrm{u}}$, found that the influence of density increases with increasing $C_{\mathrm{u}}$; their observation is not replicated in the datasets considered here. The CSDs for the bilinear gradients (BL15 and BL50) are similar to each other and lie between the $C_{\mathrm{u}} 3$ and $C_{\mathrm{u}} 1 \cdot 5$ data, but closer to the $C_{\mathrm{u}}$ 3 (indicating that the finest portion of the PSD has a greater impact on the CSD than the larger particle sizes). Again this is in agreement with the data presented in Shire \& O'Sullivan (2016). For clarity the horizontal axis is curtailed at a constriction diameter equal to the PSD $D_{0}$; a small proportion (less than $1 \%$ ) of the constrictions have diameters between $D_{0}$ and $1.5 \times D_{0}$.

There is some sensitivity to particle shape, as illustrated in Fig. 3(b); glass bead samples produced fewer small constrictions and also fewer large constrictions than sands, producing CSDs with a steeper central portion and with longer 'tails' at the upper and lower extremes. Referring to Fig. 4, this discrepancy between sands and glass beads occurs because the irregular sand particles are able to interlock, increasing the likelihood of small constrictions, and are also more likely to form large open voids, increasing the 


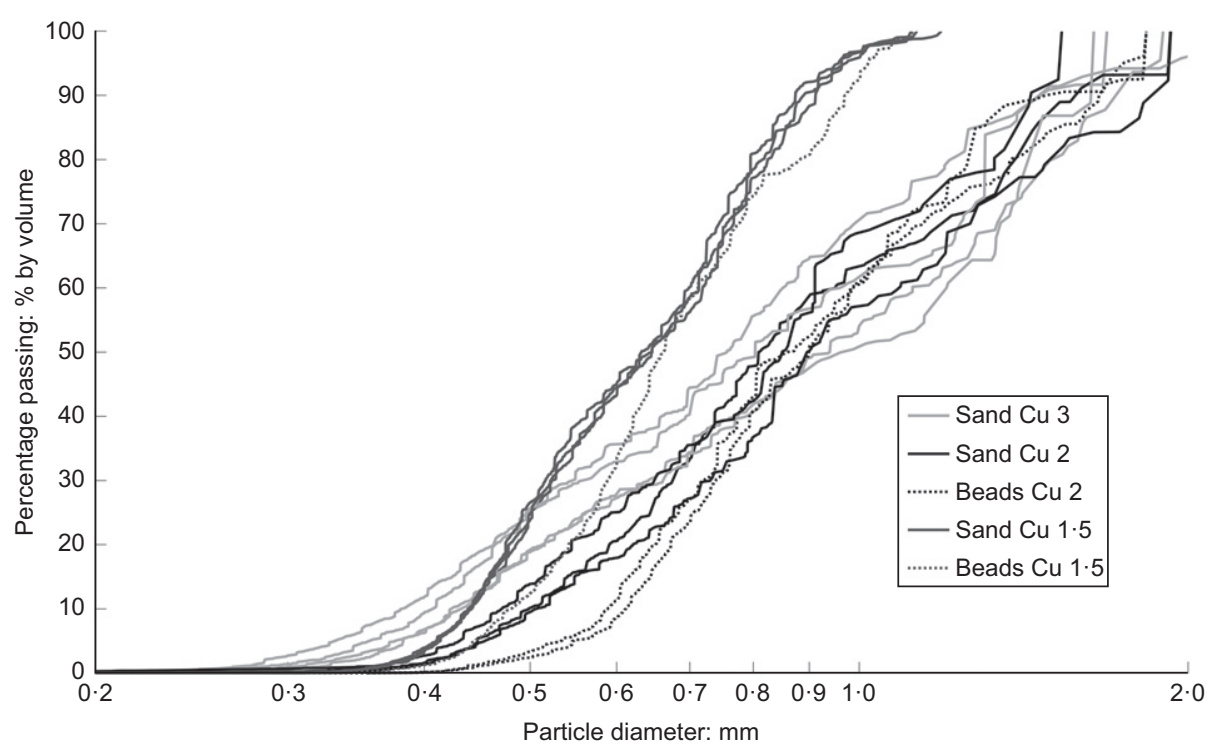

(a)

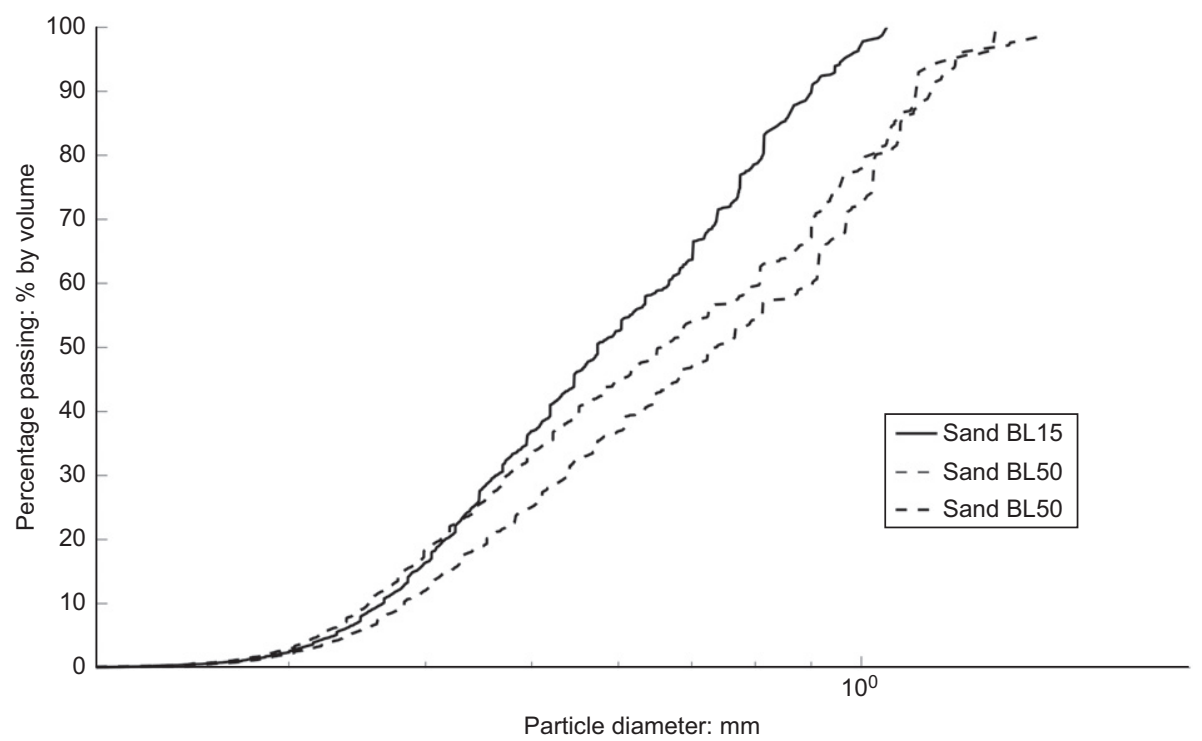

(b)

Fig. 1. Particle size distribution data: (a) for scanned specimens with approximately linear PSDs; (b) for scanned specimens with approximately bilinear PSDs

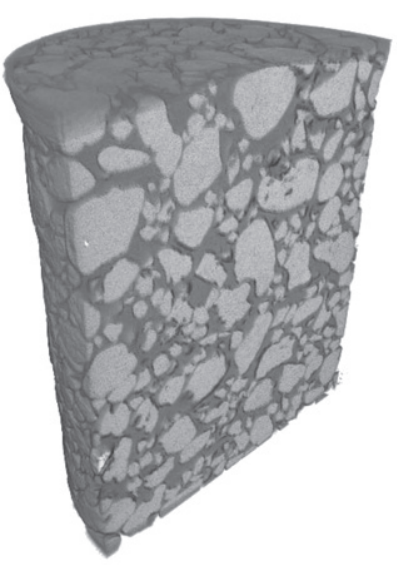

Cu 3 - sand

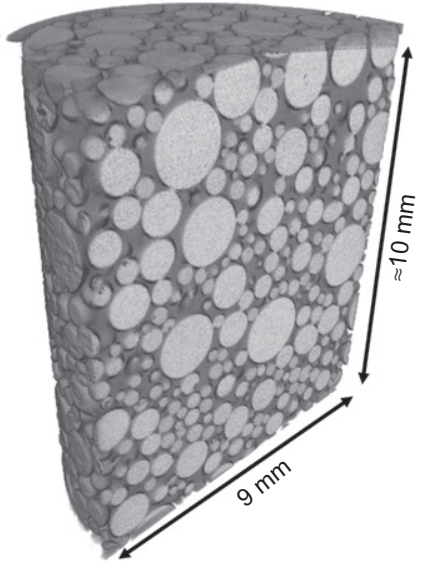

Cu 3 - glass beads

Fig. 2. Representative scan images

likelihood of very large constrictions. Based on observation of laboratory filter tests, Wu et al. (2012) also noticed that larger constrictions can form in angular sand when compared with natural rounded sand and glass beads, but they observed little difference at the finer end.

There are many image-processing steps applied to the microCT data, some of which include user-selected parameters; image artefacts can influence the data interpretation and the finer detail - that is, the smallest particles and constrictions - may be biased by resolution issues (e.g. Fonseca, 2011; Taylor, 2016). Consequently, for verification purposes, CSD results obtained by watershed analysis on a voxelised image of a DEM sample with $C_{\mathrm{u}}=3$ and similar void ratio to the dense $C_{\mathrm{u}} 3$ glass beads sample are included in Fig. 3(b). The CSD results for the DEM and glass beads samples show very good agreement, indicating that the physical specimens of glass beads were comparable with idealised spherical particle arrangements used in DEM simulations.

The use of the filter $D_{15}$ as a means to estimate filter constriction sizes has been promoted in the literature 
Table 2. Summary of data generated by way of DEM

\begin{tabular}{|c|c|c|c|c|c|c|c|}
\hline Sample & $\begin{array}{l}\text { Number of } \\
\text { particles }\end{array}$ & $D_{50}: \mu \mathrm{m}$ & $D_{10}: \mu \mathrm{m}$ & $C_{\mathrm{u}}$ & $e$ & $\begin{array}{l}\text { Coordination } \\
\text { number }\end{array}$ & $\begin{array}{c}\text { Number of } \\
\text { constrictions analysed }\end{array}$ \\
\hline $\mathrm{Cu} 1 \cdot 2$ dense & 8262 & 60 & $51 \cdot 9$ & $1 \cdot 2$ & $0 \cdot 558$ & $5 \cdot 99$ & 33553 \\
\hline $\mathrm{Cu} 1 \cdot 2$ loose & 8262 & 60 & $51 \cdot 9$ & $1 \cdot 2$ & $0 \cdot 714$ & $4 \cdot 32$ & 24742 \\
\hline $\mathrm{Cu} 1.5$ dense & 9313 & $150 \cdot 1$ & $108 \cdot 5$ & $1 \cdot \overline{5}$ & 0.531 & $5 \cdot 76$ & 35364 \\
\hline $\mathrm{Cu} 1.5$ loose & 9313 & $150 \cdot 1$ & $108 \cdot 5$ & $1 \cdot 5$ & 0.658 & 3.97 & 27732 \\
\hline $\mathrm{Cu} 2$ dense & 12115 & $99 \cdot 9$ & $57 \cdot 5$ & $2 \cdot 0$ & $0 \cdot 467$ & $5 \cdot 48$ & 42412 \\
\hline $\mathrm{Cu} 2$ loose & 12115 & $99 \cdot 9$ & $57 \cdot 5$ & $2 \cdot 0$ & $0 \cdot 555$ & $3 \cdot 38$ & 34405 \\
\hline $\mathrm{Cu} 3$ dense & 22600 & $149 \cdot 3$ & $62 \cdot 5$ & $3 \cdot 0$ & $0 \cdot 382$ & $5 \cdot 06$ & 57499 \\
\hline Cu 3 loose & 22600 & $149 \cdot 3$ & $62 \cdot 5$ & $3 \cdot 0$ & $0 \cdot 455$ & $2 \cdot 53$ & 43422 \\
\hline $\mathrm{Cu} 4 \cdot 5$ dense & 44821 & $212 \cdot 8$ & $66 \cdot 8$ & $4 \cdot 5$ & $0 \cdot 320$ & $4 \cdot 78$ & 86255 \\
\hline $\mathrm{Cu} 4 \cdot 5$ loose & 44821 & $212 \cdot 8$ & $66 \cdot 8$ & $4 \cdot 5$ & $0 \cdot 384$ & $2 \cdot 13$ & 65225 \\
\hline $\mathrm{Cu} 6$ dense & 59183 & $320 \cdot 7$ & $72 \cdot 5$ & $6 \cdot 0$ & $0 \cdot 265$ & $4 \cdot 58$ & 95134 \\
\hline $\mathrm{Cu} 6$ loose & 59183 & $320 \cdot 7$ & $72 \cdot 5$ & $6 \cdot 0$ & $0 \cdot 314$ & 1.96 & 74444 \\
\hline BL5 dense & 18632 & $80 \cdot 4$ & $58 \cdot 1$ & $1 \cdot 5$ & $0 \cdot 448$ & $5 \cdot 73$ & 70515 \\
\hline BL5 loose & 18632 & $80 \cdot 4$ & $58 \cdot 1$ & $1 \cdot 5$ & $0 \cdot 519$ & $3 \cdot 89$ & 55113 \\
\hline BL15 dense & 24757 & $92 \cdot 3$ & $62 \cdot 3$ & $1 \cdot 6$ & $0 \cdot 440$ & $5 \cdot 54$ & 91965 \\
\hline BL15 loose & 24757 & $92 \cdot 3$ & $62 \cdot 3$ & $1 \cdot 6$ & $0 \cdot 500$ & $3 \cdot 74$ & 73696 \\
\hline BL25 dense & 30011 & $106 \cdot 1$ & $62 \cdot 3$ & $1 \cdot 9$ & $0 \cdot 498$ & $5 \cdot 23$ & 103239 \\
\hline BL25 loose & 30011 & $106 \cdot 1$ & $62 \cdot 3$ & $1 \cdot 9$ & $0 \cdot 584$ & $3 \cdot 32$ & 86316 \\
\hline BL50 dense & 39990 & $150 \cdot 0$ & $62 \cdot 3$ & $2 \cdot 6$ & $0 \cdot 431$ & $4 \cdot 86$ & 111267 \\
\hline BL50 loose & 39990 & $150 \cdot 0$ & $62 \cdot 3$ & $2 \cdot 6$ & $0 \cdot 503$ & $2 \cdot 52$ & 89875 \\
\hline
\end{tabular}

and engineering practice in the form of Terzaghi's filter rule (Sherard \& Dunnigan, 1989; ICOLD, 2015) and is supported by macro-scale filtration experiments (Kenney et al., 1985). Shire \& O'Sullivan (2016) found that, when the CSD data are normalised by $D_{15}$, a narrow band of CSD curves emerges for materials with a given relative density but differing $C_{\mathrm{u}}$ values. The data presented in Fig. 5 confirm that this observation holds for the physical sand samples, where the particle scale data were generated and analysed using techniques that differ from Shire and O'Sullivan's approach. Fig. 5 therefore adds weight to Shire and O'Sullivan's conclusion that there is a fundamental basis to the use of $D_{15}$ to estimate constriction diameters in engineering design.

\section{Constriction density}

The efficacy of a filter depends on the overall number of constrictions encountered by material passing through the filter, as well as the CSD. In their presentation of a contact-based approach to partition the void space for DEM datasets, O'Sullivan et al. (2015) showed that there is a link between the number of inter-particle contacts in a sample and the number of constrictions. Fig. 6(a) is a plot of the number of constrictions per $\mathrm{mm}^{3}$ against the number of contacts per $\mathrm{mm}^{3}$ considering both the microCT and DEM data. To identify the contacts, the particle phase of the microCT dataset was also subject to watershed segmentation. Voxels associated with each particle were assigned a colour index. Contacts are identified as the points where there were differing adjacent colour indices (refer to Taylor (2016) for further details). The data are plotted on a logarithmic scale as the numbers of constrictions and contacts in the samples considered vary by orders of magnitude; however, in each case there is a clear trend of an almost linear dependency of the number of constrictions per $\mathrm{mm}^{3}$ against the number of contacts per $\mathrm{mm}^{3}$. Linear constriction spacing is commonly approximated in the literature as a multiple of $D_{50}$ (Soria et al., 1993; Wu et al., 2012) and so $D_{50}^{3}$ was selected as a potential normalising volume and the normalised constriction density is defined here as $\overline{f_{\mathrm{c}}}$

$$
\overline{f_{\mathrm{c}}}=N_{\mathrm{c}}\left(\frac{D_{50}^{3}}{V}\right)
$$

where $N_{\mathrm{c}}$ is the number of constrictions and $V$ is the sample volume. Referring to Fig. 6(b) when normalised constriction and contact densities are considered a clear trend in the data is apparent with both microCT and DEM data sets giving a similar relationship.

The normalised contact density is fundamentally a particle scale parameter that cannot easily be measured in the laboratory or in situ. It is more useful to consider the link between normalised constriction density and physically measurable parameters, namely, void ratio $(e)$ and $C_{\mathrm{u}}$. Fig. 7(a) considers the normalised constriction density as a function of $e$. It is clear that the constriction density has a dependency on void ratio. Fig. 7(b) considers the same data plotted against $C_{\mathrm{u}}$ and again a clear trend is apparent. The range of attainable void ratios is dependent on $C_{\mathrm{u}}$ (Youd, 1973) as confirmed in Fig. 8, and so the shape of the PSD (the $C_{\mathrm{u}}$ value) is the strongest independent variable that governs the number of constrictions.

Assuming the constrictions to be arranged isotropically, a simple estimate of the (normalised) constriction spacing in a given direction can be obtained from $\bar{f}_{\mathrm{c}}^{(1 / 3)}$, producing results as shown in Fig. 9(a). It is clear that constriction spacing reduces as $C_{\mathrm{u}}$ increases and the DEM and microCT data are in good agreement. Referring to Soria et al. (1993) and Indraratna et al. (2007) it can be argued that $D_{50}$ (by mass or volume) gives a reasonable estimate of the constriction spacing; however, using the normalisation adopted here, the variation in spacing with $C_{\mathrm{u}}$ is not captured. Soria et al. (1993) and Indraratna et al. (2007) also consider the median diameter by number $\left(D_{50}^{\text {num }}\right)$ and the median diameter by surface area $\left(D_{50}^{\mathrm{SA}}\right)$. For the microCT data $D_{50}^{\mathrm{SA}}$ was determined from the PSD following Trani \& Indraratna (2010), and $D_{50}^{\text {SA }}$ was directly calculated for the DEM data. Referring to Fig. 9(b) for both the DEM and microCT data, although $D_{50}^{\text {num }}$ and $D_{50}^{\mathrm{SA}}$ (normalised by $D_{50}$ ) capture the variation in constriction spacing with $C_{\mathrm{u}}$, they overestimate the spacing at lower $C_{\mathrm{u}}$ values, particularly in the case of $D_{50}^{\mathrm{SA}}$.

Wu et al. (2012) and Sjah \& Vincens (2013) indicate that the constriction spacing $(s)$ can be estimated as

$$
s=\sqrt[3]{\frac{e}{e_{\text {maxspheres }}}} s_{\text {maxspheres }}
$$




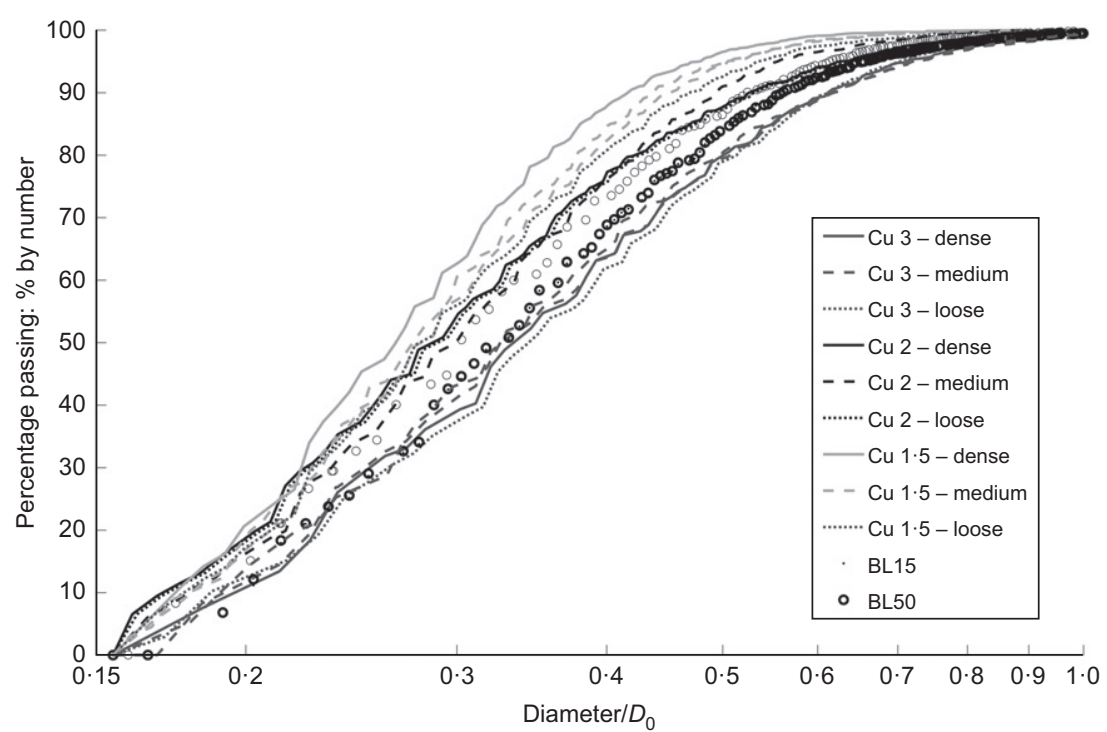

(a)

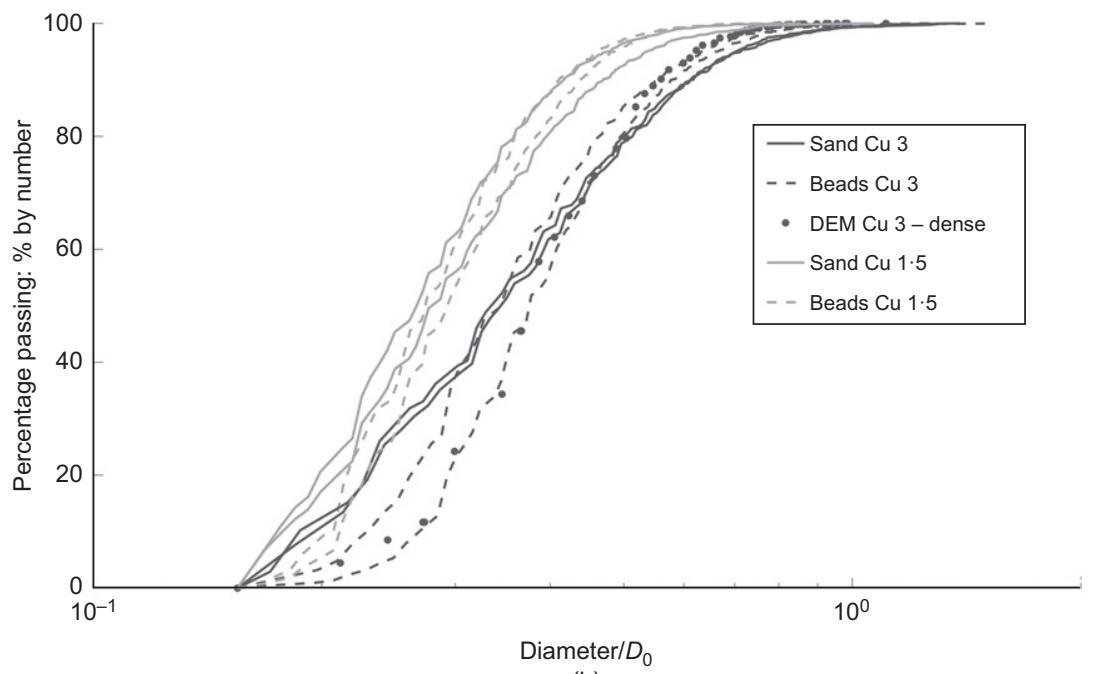

(b)

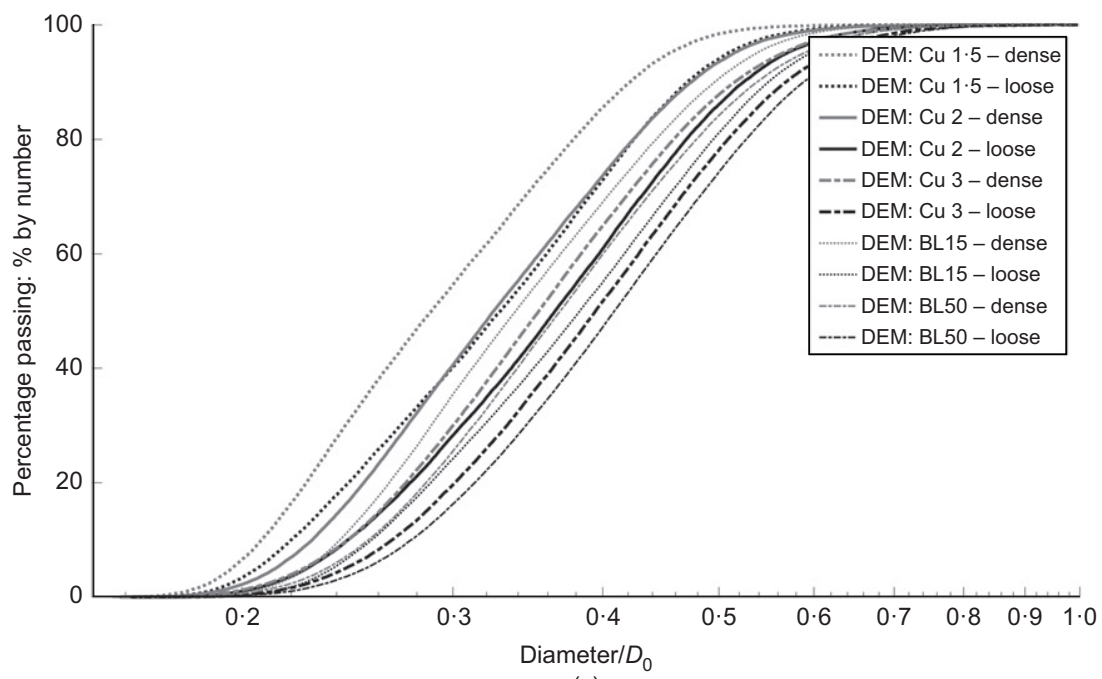

(c)

Fig. 3. CSD data normalised by $D_{0}$ : (a) microCT data showing effect of varying density and $C_{\mathrm{u}}$-sand samples; (b) microCT data showing effect of varying particle shape; (c) representative CSD data from DEM analyses (Shire \& O'Sullivan, 2016)

where $s_{\text {maxspheres }} \approx 0.5 D_{50}^{\mathrm{SA}}$ and $D_{50}^{\mathrm{SA}}$ is the median diameter from a PSD by surface area. For the DEM data $e_{\text {maxspheres, }}$ the maximum void ratio estimated for spherical particles with the same $C_{\mathrm{u}}$, was calculated using the expression for porosity ( $n_{\text {maxsphere }}$ ) given in Kovacs (1981)

$$
n_{\text {maxsphere }}=0 \cdot 287+0 \cdot 143 e^{-\left(C_{\mathrm{u}}-1\right) / 2}
$$






(a)
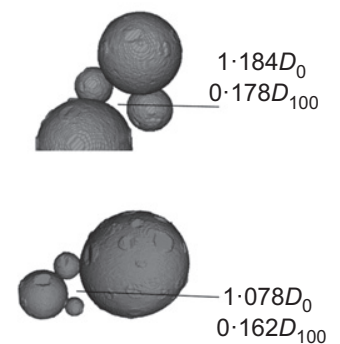

(b)

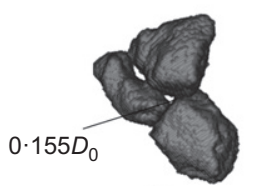

$0 \cdot 155 D_{0}$



(c)
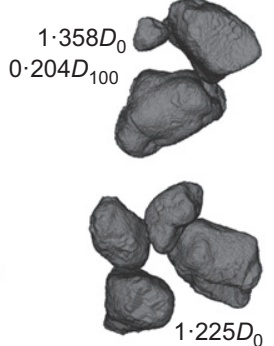

$0 \cdot 184 D_{100}$

(d)

Fig. 4. Comparison of representative particle configurations that produce the largest and smallest constrictions for samples with $C_{\mathrm{u}} \approx 3$ : (a) smallest constrictions - glass bead specimens; (b) largest constrictions - glass bead sample; (c) smallest constrictions - sand specimens; (d) largest constrictions - sand specimen (note: configurations are not drawn to a uniform scale)

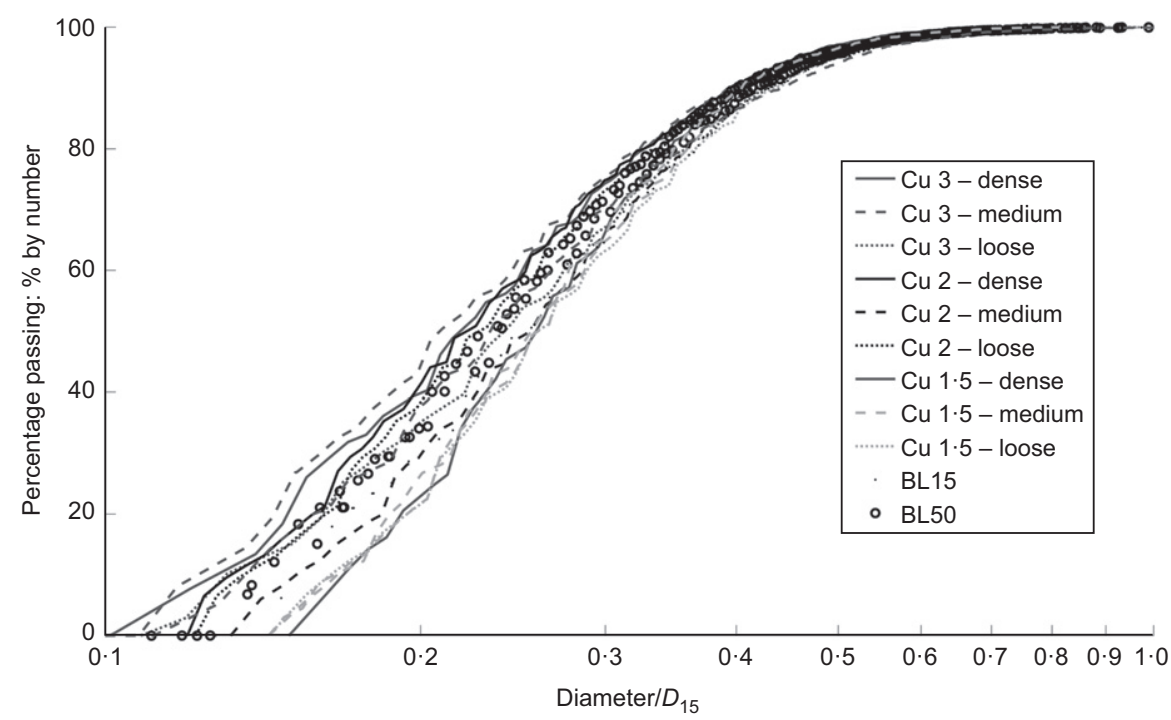

(a)

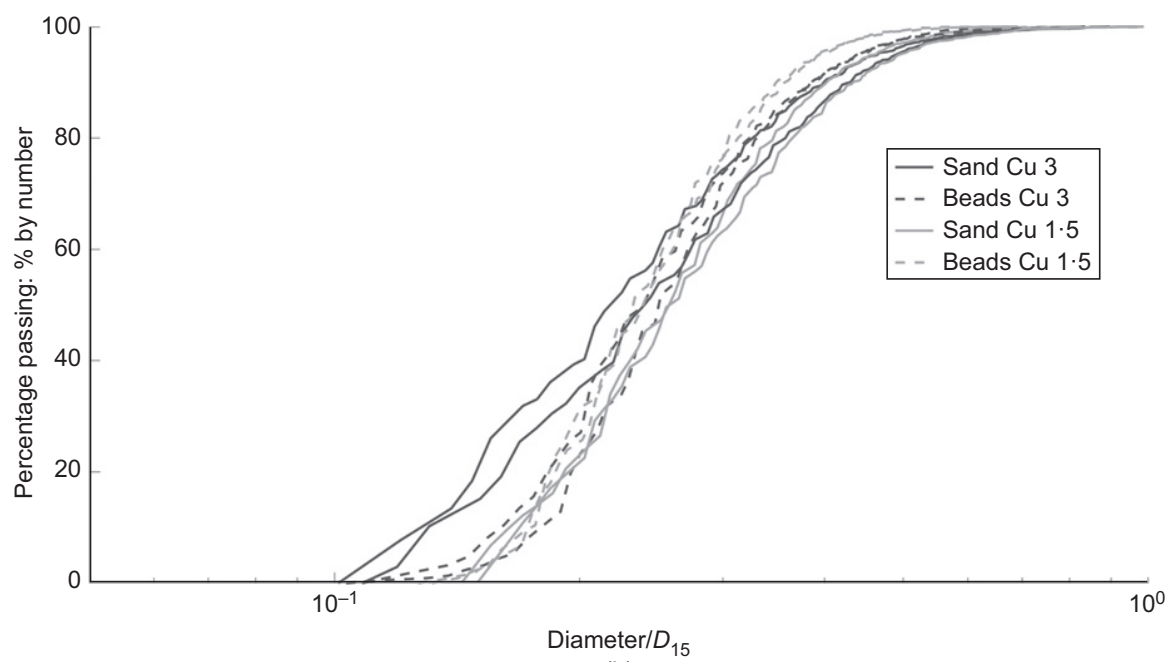

(b)

Fig. 5. Constriction size distributions from microCT normalised by $D_{15}$ : (a) sand samples; (b) comparison of sand and glass bead samples

For the DEM data, the maximum void ratio values given in Shire \& O’Sullivan (2016) were used. Referring to Fig. 9(b), estimates of constriction spacing obtained using equation (2) (normalised by $D_{50}$ ) are in good agreement with the spacing values obtained using the constriction density in both the microCT and DEM datasets.

\section{CONCLUSIONS}

(a) The good agreement between the data obtained using microCT images and data obtained from DEM simulations support the use of DEM to analyse granular filters for geotechnical applications. 




(a)

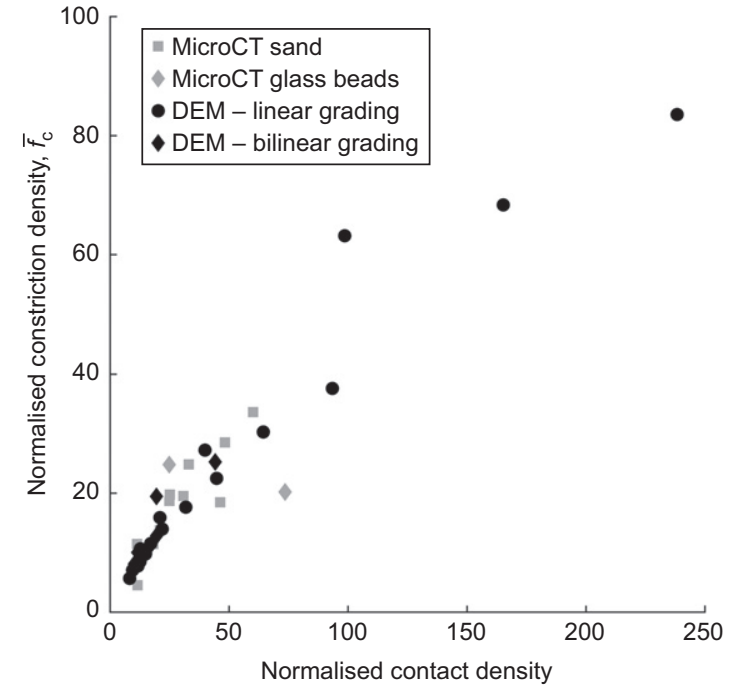

(b)

Fig. 6. Relationship between number of contacts and number of constrictions: (a) number of constrictions plotted against number of contacts; (b) normalised constriction density plotted against normalised contact density

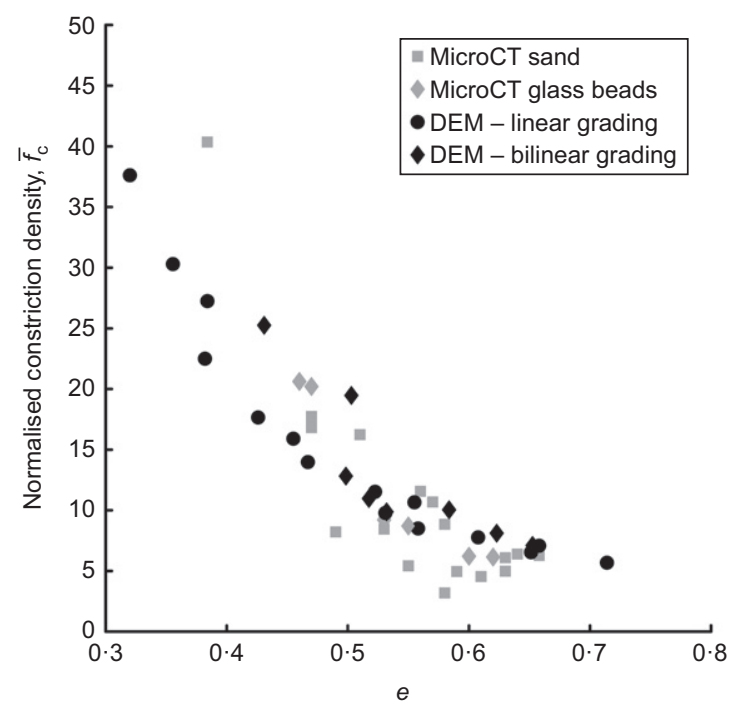

(a)

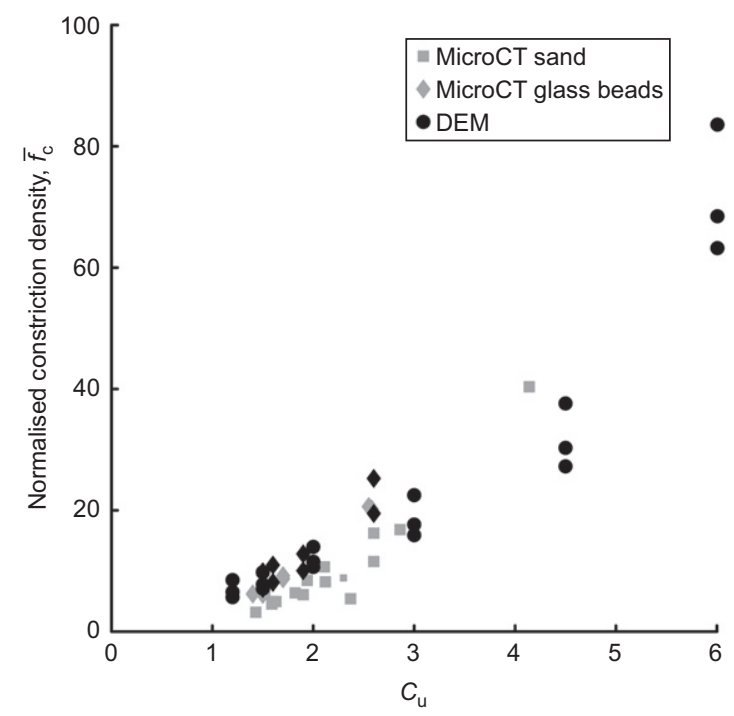

(b)

Fig. 7. Constriction density as a function of (a) void ratio, $e$, and (b) $C_{\mathrm{u}}$

(b) The distribution of constriction sizes is more sensitive to the distribution of particle sizes than to changes in shape or density. There is some shape sensitivity; the data indicate that angular particles can form more very small and very large constrictions in comparison with spherical equivalents. The microCT data confirm the idea that the particle diameter $D_{15}$ provides an effective indication of constriction sizes; normalisation of the CSDs by $D_{15}$ produced a narrow range of curves. These data thus support the use of $D_{15}$ in the filter rules adopted in engineering practice.

(c) There is a link between the number of contacts in a specimen and the number of constrictions. When quantifying constriction density it is not sufficient to consider a density per unit volume, as the particle size relative to the sample size must also be considered. Here clear trends in the data emerged by considering the constriction density normalised by $D_{50}^{3}$. There is a clear relationship between normalised constriction density and both void ratio and $C_{\mathrm{u}}$. As the range of attainable void ratios depends on $C_{\mathrm{u}}$, it is the $C_{\mathrm{u}}$

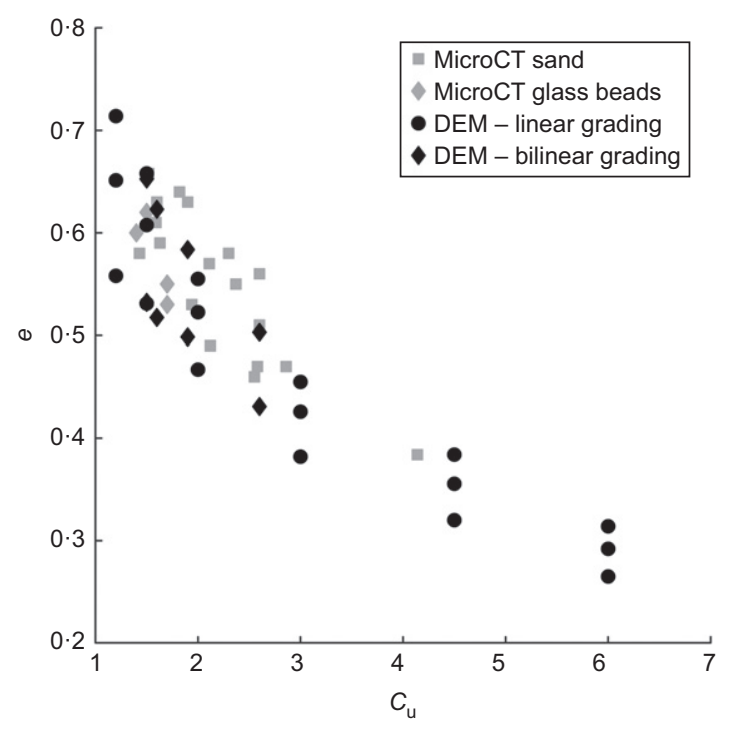

Fig. 8. Void ratio- $C_{\mathrm{u}}$ relationship 


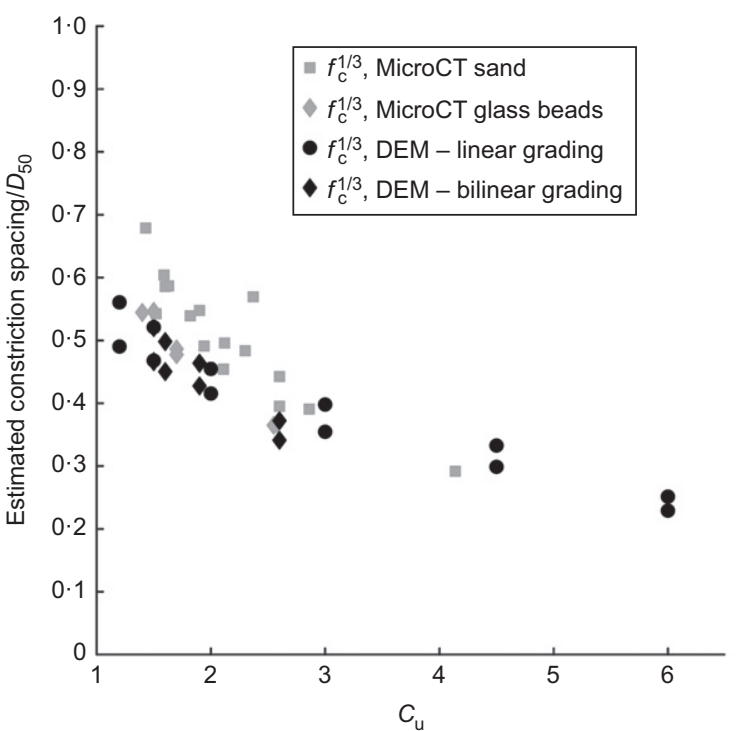

(a)

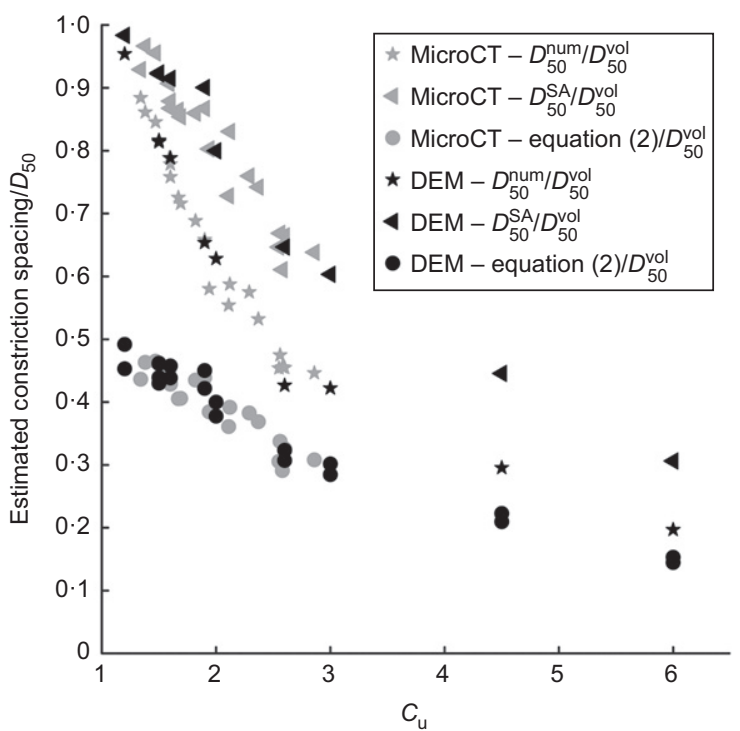

(b)

Fig. 9. Comparison of estimated spacing based on constriction density with approximations proposed in the literature: (a) variation in constriction spacing with $C_{\mathrm{u}}$ obtained from DEM and microCT data; (b) variation in constriction spacing with $C_{\mathrm{u}}$ obtained by using empirical and semiempirical expressions proposed in the literature

(or rather the PSD) that is the most significant variable determining constriction density.

(d) The data indicate a link between constriction spacing and $C_{\mathrm{u}}$ that has not been apparent in previous studies. The expression for constriction spacing proposed by Wu et al. (2012) and Sjah \& Vincens (2013) is supported by the data presented here.

(e) The data presented can inform the development of network models to predict permeability (e.g. Bryant et al., 1993) or filtration (e.g. Shire \& O'Sullivan, 2017).

( $f$ ) The data considered here are ideal; the physical samples were prepared by dry deposition and the numerical samples are perfectly isotropic (they lack any inherent anisotropy); consequently, further analyses are required to establish whether the relationship depends on depositional fabric and to what extent compaction and other processes will influence the results.

\section{ACKNOWLEDGEMENTS}

Dr Simon Carr of Queen Mary University London facilitated the microCT data acquisition. The doctoral research studies of both Dr Taylor and Dr Shire were funded by the Engineering and Physical Sciences Research Council (EPSRC) studentships.

\section{NOTATION}

$C_{\mathrm{u}}$ coefficient of uniformity, $=D_{60} / D_{10}$

$D_{0} \quad$ smallest particle diameter

$D_{10} \quad$ 10th percentile particle diameter; $10 \%$ of the particles (by volume) are smaller than this diameter

$D_{15} \quad 15$ th percentile particle diameter; $15 \%$ of the particles (by volume) are smaller than this diameter

$D_{50}$ median particle diameter; $50 \%$ of the particles (by volume) are smaller than this diameter

$D_{50}^{\text {num }} \quad$ median particle diameter considering number distribution; $50 \%$ of the particles (by number) are smaller than this diameter

$D_{50}^{\mathrm{SA}}$ median particle diameter considering surface area; $50 \%$ of the particles (by surface area) are smaller than this diameter

$D_{60} \quad 60$ th percentile particle diameter; $60 \%$ of the particles (by volume) are smaller than this diameter $e$ void ratio

$e_{\text {maxspheres }}$ maximum void ratio for spherical packing with a given $C_{\mathrm{u}}$

$\overline{f_{\mathrm{c}}}$ normalised constriction density

$N_{\mathrm{c}}$ number of constrictions

$n_{\text {maxsphere }}$ maximum porosity for spherical packing with a given $C_{\mathrm{u}}$

$s$ constriction spacing

$s_{\text {maxspheres }}$ spacing of particles for spherical packing with a given $C_{\mathrm{u}}$ and maximum void ratio

$V$ sample volume

\section{REFERENCES}

Al-Raoush, R., Thompson, K. \& Willson, C. S. (2003). Comparison of network generation techniques for unconsolidated porous media. Soil Sci. Soc. Am. J. 67, No. 6, 1687.

Bryant, S. L., King, P. R. \& Mellor, D. W. (1993). Network model evaluation of permeability and spatial correlation in a real random sphere packing. Transport in Porous Media 11, No. 1, 53-70.

FEIVSG (FEI Visualization Sciences Group) (2012). Avizo Fire 7.0.1. Hillsboro, OR, USA: FEIVSG.

Fonseca, J. (2011). The evolution of morphology and fabric of a sand during shearing. $\mathrm{PhD}$ thesis, Imperial College London, London, UK.

Fonseca, J., O’Sullivan, C., Coop, M. R. \& Lee, P. D. (2012). Non-invasive characterization of particle morphology of natural sands. Soils Found 52, No. 4, 712-722.

ICOLD (International Commission on Large Dams) (2015). Internal erosion of existing dams, levees and dikes, and their foundations. In Bulletin 164, volume 1: internal erosion processes and engineering assessment. Paris, France: ICOLD.

Indraratna, B., Raut, A. K. \& Khabbaz, H. (2007). Constrictionbased retention criterion for granular filter design. J. Geotech. Geoenviron. Engng 133, No. 3, 266-276.

Indraratna, B., Nguyen, V. T. \& Rujikiatkamjorn, C. (2012). Hydraulic conductivity of saturated granular soils determined using a constriction-based technique. Can. Geotech. J. 49, No. 5, 607-613.

Kenney, T. C., Chahal, R., Chiu, E., Ofoegbu, G. I., Omange, G. N. \& Ume, C. A. (1985). Controlling constriction sizes of granular filters. Can. Geotech. J. 22, No. 1, 32-43.

Kézdi, Á. (1979). Soil physics: selected topics. Amsterdam, the Netherlands: Elsevier.

Kovacs, G. (1981). Seepage hydraulics. Amsterdam, the Netherlands: Elsevier. 
NikonMetrology (2013). CT Pro 3D. Brighton, MI, USA: NikonMetrology.

O’Sullivan, C., Bluthé, J., Sejpar, K., Shire, T. \& Cheung, L. Y. G. (2015). Contact based void partitioning to assess filtration properties in DEM simulations. Comput. Geotech. 64, 120-131, https://doi.org/10.1016/j.compgeo.2014.11.003.

Plimpton, S. (1995). Fast parallel algorithms for short-range molecular-dynamics. J. Comput. Physics 117, No. 1, 1-19.

Rasband, W. S. (2012). ImageJ. Bethesda, MD, USA: U. S. National Institutes of Health. See https://imagej.nih.gov/ij/ (accessed 16/04/2018)

Reboul, N., Vincens, E. \& Cambou, B. (2010). A computational procedure to assess the distribution of constriction sizes for an assembly of spheres. Comput. Geotech. 37, No. 1-2, 195-206.

Sherard, J. L. \& Dunnigan, L. P. (1989). Critical filters for impervious soils. J. Geotech. Engng 115, No. 7, 927-947.

Shire, T. (2014). Micro-scale modelling of granular filters. PhD thesis, Imperial College London, London, UK.

Shire, T. \& O'Sullivan, C. (2016). Constriction size distributions of granular filters: a numerical study. Géotechnique 66, No. 10, 826-839, https://doi.org/10.1680/jgeot.15.P.215.

Shire, T. \& O'Sullivan, C. (2017). A network model to assess base-filter combinations. Comput. Geotech. 84, 117-128.

Shire, T., O'Sullivan, C., Taylor, H. \& Sim, W. (2016). Measurement of constriction size distributions using three grain-scale methods. In Scour and erosion (eds J. Harris, R. Whitehouse and S. Moxon), pp. 1067-1074. Leiden, the Netherlands: CRC Press/Balkema.

Sjah, J. \& Vincens, E. (2013). Determination of the constriction size distribution of granular filters by filtration tests. Int. J. Numer. Analyt. Methods Geomech. 37, No. 10, 1231-1246.
Soria, M. H., Aramaki, R. T. \& Viviani, E. (1993). Experimental determination of void size curves. In Filters in geotechnical and hydraulic engineering (eds J. Brauns, M. Heibaum and U. Schuler), pp. 43-48. Rotterdam, the Netherlands: Balkema.

Taylor, H. (2016). Assessing the potential for suffusion in sands using $X$-ray micro-CT images. $\mathrm{PhD}$ thesis, Imperial College London, London, UK.

Taylor, H. F., O’Sullivan, C. \& Sim, W. W. (2015). A new method to identify void constrictions in micro-CT images of sand. Comput. Geotech. 69, 279-290.

Taylor, H. F., O'Sullivan, C., Sim, W. \& Carr, S. J. (2017). Sub-particle-scale investigation of seepage in sands. Soils Found. 57, No. 3, 439-452.

Trani, L. D. O. \& Indraratna, B. (2010). The use of particle size distribution by surface area method in predicting the saturated hydraulic conductivity of graded granular soils. Géotechnique 60, No. 12, 957-962, https://doi.org/10.1680/geot.9.T.014.

Vincens, E., Reboul, N. \& Cambou, B. (2013). The process of filtration in granular materials. In Erosion of geomaterials (ed. S. Bonelli), pp. 81-114. London, UK: Wiley-ISTE.

$\mathrm{Wu}$, L., Nzouapet, B. N., Vincens, E. \& Bernat-Minana, S. (2012). Laboratory experiments for the determination of the Constriction Size Distribution of granular filters. In Proceedings of the 6th international conference on scour and erosion, ICSE-6, pp. 233-240. Paris, France: SHF.

Youd, T. L. (1973). Factors controlling maximum and minimum densities of sands. In Evaluation of relative density and its role in geotechnical projects involving cohesionless soils (eds E. T. Sellig and R. S. Ladd), ASTM Special Technical Publication 523, pp. 98-112. West Conshohocken, PA, USA: ASTM International. 